\title{
Acabou a
}

\section{"perestróika'?}

\section{LENINA POMERANZ}

A tempestuosa e conflitiva evolução dos acontecimentos econômicos e políticos na URSS tem conduzido a recorrentes afirmações sobre o fim da perestroika. Vinculamse estas afirmações aos rumos seguidos pelos acontecimentos no período mais recente, de final do ano passado até o presente, os quais, sem dúvida, indicam algumas mudanças de rumo em relação ao curso anterior. Estas mantêm e acentuam as indagações sobre a perestróika e seu destino; mas é preciso examinar um pouco mais cuidadosamente o processo de implantação dela, antes de se tirar conclusões.
LENINA POMERANZ é professora da FEA-USP e coordenadora cientffica do NAP-Centro de Estudos dos Palses Socialistas em Transformação da USP. É autora do livro Elaboração e análise de projetos (Hucitec).

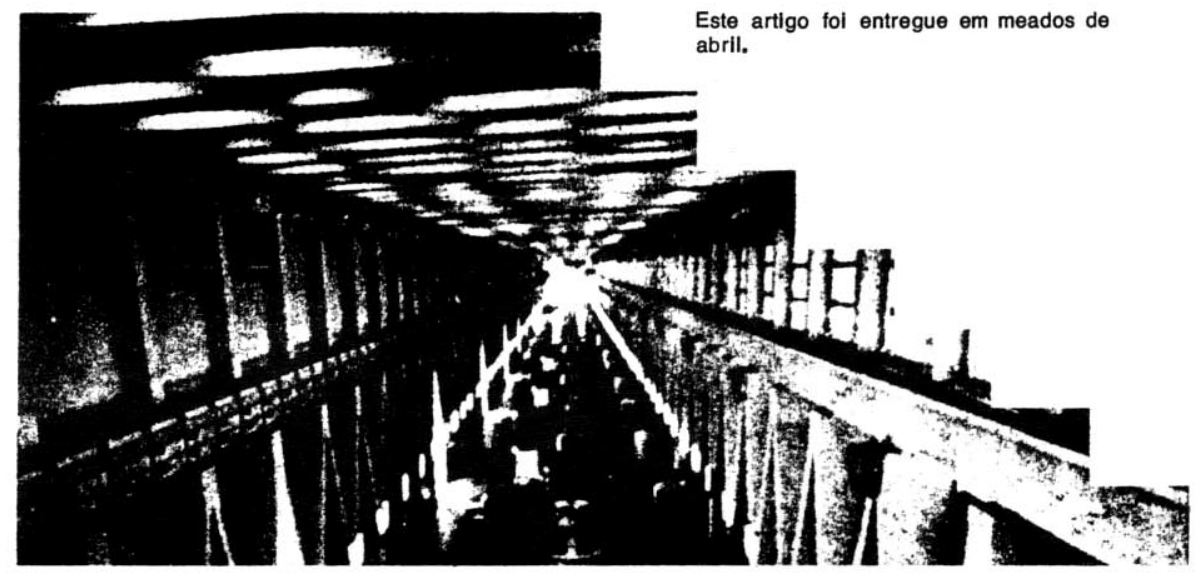

A perestróka foi lançada em 1987 , como uma plataforma de reconstrução do sistema. Ela compreendia uma reforma econômica e uma reforma político-institucional, e apoiava-se num processo de abertura democrática, a glasnost, que, permitindo ampla discussão do processo de transformação social do país, deveria ancorar as suas mudanças polf́tico-institucionais.

A perestroika no plano interno fez-se acompanhar pela adoção de uma mudança na política externa da URSS que tinha por objetivo, a partir do desarmamento e da cooperação internacional, associar o país ao processo de integração européia, integrá-lo na chamada Casa Comum Européia.

A reforma econômica tinha como centro a introdução dos mecanismos de mercado definido este como um mercado regulado - e deveria ser implantada através de dois caminhos: a descentralização do processo decisório e a criação do referencial macroeconômico para regulamentação indireta desse processo, a criação do que na literatura soviética especializada se denomina os instrumentos econômicos (ekonomitcheskie ritchagui) de gestão da economia, em contraposição aos métodos de gestão administrativa centralizada (komando-administrativnie metodi upravlenia). A reforma pressupunha, portanto, uma reestruturação dos órgãos centrais de gestão, dando-lhes outras funções (caso da Gosplan, a comissão central de planejamento) e/ou eliminando-os (caso dos ministérios setoriais e administraçōes intermediárias, como o Comitê Agroindustrial, por exemplo).

A reforma política pretendia uma separação dos poderes do Partido Comunista e do Estado, e contemplava reformas constitucionais para a modificação do sistema eleitoral e de governo.
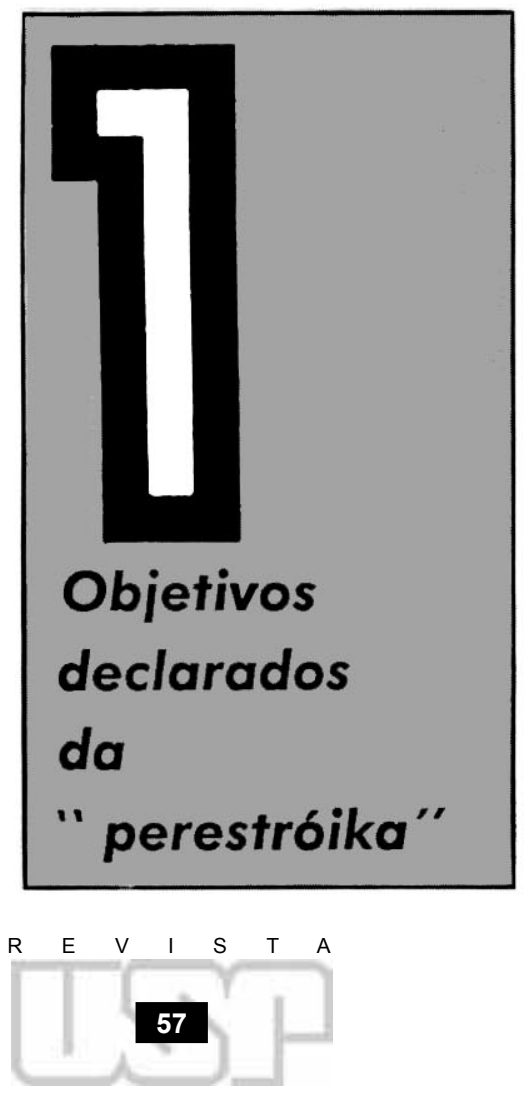

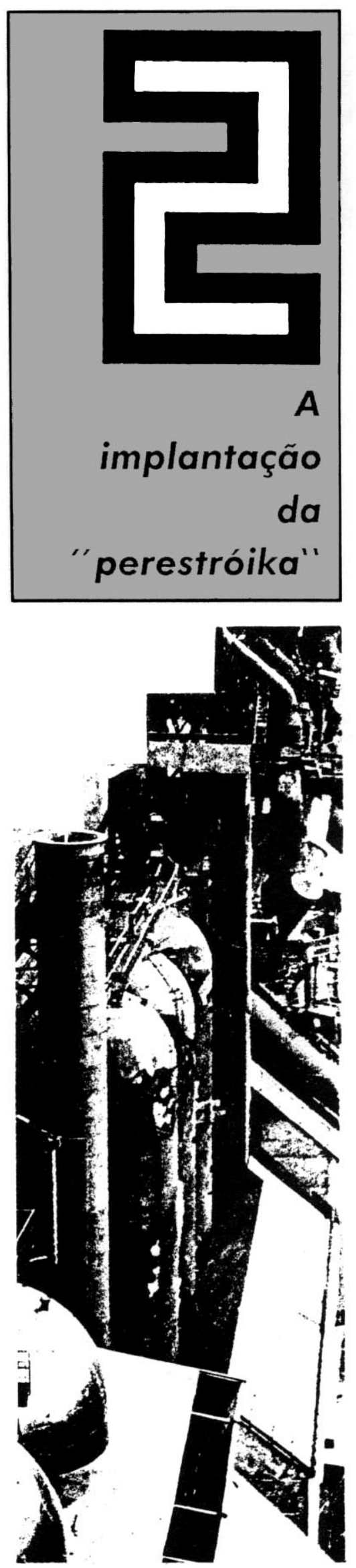

A implantação da perestroika iniciou-se de forma tímida e veio se realizando num processo de ajustamento gradativo. No que se refere à reforma econômica, o processo realizou-se em descompasso entre as suas duas linhas de atuação. A descentralização do processo decisório processou-se mais rapidamente, ainda que parcialmente; abrangeu a introdução de institutos legais para a atividade descentralizada das empresas, mas manteve relativamente intocados os órgãos centrais de gestão. Os institutos legais evolúram desde as primeiras leis sobre a empresa estatal, o arrendamento, as cooperativas e o trabalho individual, até a lei sobre a propriedade e as demais leis complementares sobre a empresa, a S/A e a sociedade por cotas, a lei sobre a pequena e a média empresa, criando, assim, as bases para o estabelecimento dos direitos de propriedade. Daf́ em diante, começam as discussões sobre as formas de propriedade e os procedimentos de desestatização e privatização de empresas. Em relação ao capital estrangeiro, a legislação evoluiu da autorização inicial para a criação de joint ventures bastante restritivas, para a legalização do investimento estrangeiro sem necessidade do sócio soviético e para a sua garantia expressa na Lei sobre a Propriedade.

Um balanço consolidado da aplicação destas leis não existe. Dados isolados publicados na imprensa especializada dão conta: a) da atuação, em junho de 1990 , de cerca de 2.000 empresas em regime de arrendam ento no setor industrial, 1.000 no setor da construção, 1.300 no comércio e serviços pessoais e 32.000 unidades produtivas na agricultura, empregando um total de mais de 7 milhões de pessoas. A União dos Arrendatários congregava na ocasião aproximadamente 6.000 empresas $^{(1)}$; b) do funcionamento, no primeiro semestre de 1990 , de $209,7 \mathrm{mil}$ cooperativas, empregando 5.219,5 mil pessoas e realizando um volume de vendas de $27.268,1$ milhões de rublos no semestre considerado, dos quais $3.543,2$ milhões de vendas diretas à população(2); c) de que as experiências de transformação de empresas estatais em S/As ainda são isoladas; d) de que, em relação ao capital estrangeiro, afora os grandes investimentos anunciados no decorrer de 1990, particularmente no setor do petróleo, de acordo com análise publicada em começo de 1990 estavam registradas, no Ministério das Finanças nessa ocasião, 1.274 joint ventures, com um capital de 3,3 bilhões de rublos. Dessas empresas, porém, somente 184 estavam já em funcionamento no terceiro trimestre de 1989, com um volume de vendas da ordem de 605 milhões de rublos ${ }^{(3)}$; não há informações sobre o andamento das privatizações. Em texto apresentado a uma conferência organizada pelo Instituto Fernand Braudel no Brasil, entre 8 e 12 de abril de 1991, A. Golovkov e K. Kagalovski, do Centro Internacional de Pesquisas sobre as Reformas Econômicas, de Moscou(4) referem-se ao começo de um "vigoroso processo de privatização espontâneo (incontrolado)... conduzido por enérgicos diretores de empresas e outros membros do establishment estatal e partidário que estão tentando ajustar-se às mutantes realidades e preservar suas rendas e autoridade". Mas não dão informações quantitativas sobre esse processo de privatização.

O balanço, como se pode concluir, comparando os números acima com os dados do Produto Social Bruto (1.568,6 bilhões de rublos) e da população ocupada (127 milhões de pessoas) relativos a $1989^{(5)}$, parece bastante modesto.

As causas para essa perfórmance também não são facilmente detectáveis; além dos elementos de ordem econômica - ausência do referencial macroeconômico, insuficiência de oferta - e resistência do aparato administrativo às reformas, assumiu papel relevante mais recentemente a chamada "guerra das leis", que reflete a indefinição de competências entre o governo central e as repúblicas para regulamentar a propriedade dos recursos e sua utilização; em outros termos, para definir o comportamento das empresas no processo de adaptação às reformas proclamadas nos diferentes institutos legais.

De qualquer forma, independentemente da forma de propriedade assumida pelas empresas, as novas leis outorgam maior autonomia à sua atividade, quebrando ainda que parcialmente sua dependência dos órgãos centrais. Entre as conseqüências mais imediatas dessa autonomia cabe destacar, na linha de raciocínio aqui desenvolvida, a busca de soluções próprias à obtenção de recursos materiais e financeiros. Essas soluções corporificam-se na constituição de cooperativas subsidiárias como uma das formas de conversão da moeda de conta em moeda corrente ${ }^{(6)}$ e na colocação e aquisição de excedentes de insumos anteriormente estocados nas recém-constitúfdas Bolsas de Mercadorias.

No âmbito macroeconômico pouco ou quase nada se avançou. O referencial macroeconômico indispensável ao funcionamento dos mecanismos de mercado pressupõe o estabelecimento de um sistema de preços relativos equilibrado, portanto uma reforma de preços; e de um sistema monetário e creditício eficiente, portanto uma reforma do sis-

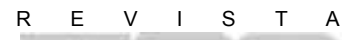


tema bancário; e, naturalmente, um sistema fiscal adequado.

Nas condiçōes históricas de funcionamento do sistema, marcado por crônica escassez de recursos, sua alocação se realiza centralizadamente, em termos físicos, não desempenhando os preços senão uma função passiva. Dadas as dificuldades de manter centralizada a formação de preços em uma economia complexa, dada a pressão de demanda e os sistemas vigentes de estímulo à atividade empresarial, foram sendo introduzidos desequilibrios na formação de diferentes preços, que acentuaram o desequilíbrio setorial existente, expresso nos preços irreais dos alimentos e outros produtos essenciais altamente subsidiados, e no baixo preço relativo dos insumos básicos, entre outros. A reforma dos preços, além de ser uma tarefa extremamente complexa e delicada em si mesma, foi amplamente debatida não só pela comunidade técnica, mas também na imprensa falada e escrita, com isso acrescentando dificuldades políticas à sua implementação.

A reforma do sistema bancário, aparentemente mais fácil, iniciou-se com a transformação do Banco Estatal em Banco Central e a criação de bancos comerciais num sistema de dois níveis; mas o seu funcionamento em novas bases pressupõe uma modificação nas relações financeiras entre as empresas e entre estas e os bancos que elimine a moeda de conta e assegure uma real autonomia financeira às empresas. Para isso, entretanto, seria necessário que se completasse o processo de estabelecimento de relações contratuais diretas entre as empresas, bastante dificultado pelas restrições generalizadas de oferta e as incertezas a ela associadas, nas condições atuais de funcionamento da economia soviética. Finalmente, quanto ao sistema fiscal, a sua reforma está estreitamente vinculada à reestruturação da economia, na medida em que se redefinem as funções do Estado e se deve, por um lado, reduzir as dimensões e o papel do orçamento estatal na economia e, por outro, passar a utilizar a política fiscal como instrumento de política econômica. As dificuldades não se restringem, porem, aos aspectos estruturais da reforma. A estas devem ser acrescentadas as dificuldades de ordem conjuntural, vinculadas ao processo de transição para os novos métodos de gestão, que resultam das pressões exercidas sobre o orçamento pelo aumento das importações em fase de queda das receitas de exportação e da desorganização econômica vigente. Esta, expressa no desabastecimento generalizado, na expansão acelerada do mercado negro e na fuga do rublo, pode ser atribuída ao descompasso referido anteriormente entre o grau de descentralização decisória concedido às empresas e a criação do referencial macroeconômico, e às dificuldades de ordem polf́tica a que se fará referência mais adiante. $\mathrm{O}$ mecanismo utilizado para concessão de autonomia às empresas, na ausência de instrumentos de política monetária, conduziu, juntamente com uma grande expansão do crédito, a uma perda de controle sobre o crescimento dos fundos de salário e sobre o meio circulante, gerando pressões sobre a demanda, particularmente por bens de consumo. As incertezas, relacionadas com a desorganização do anterior sistema de suprimento centralizado e as discussões sobre a reforma dos preços, interpretada como sinônimo de sua elevação generalizada, conduziram, por sua vez, a uma queda da produção, à estocagem doméstica e empresarial de bens e insumos, ao barter (trocas diretas de bens), e ao crescimento do mercado negro, com isso caracterizando a desorganização econômica referida.

$\mathrm{O}$ processo é retroalimentador, na medida em que caem as receitas do governo - pela descentralização iniciada e pela queda da produção - e crescem os seus dispêndios para cobrir maiores gastos sociais e a importação de bens de consumo entre outros - e o déficit público é ilimitadamente financiado por crédito do Banco Estatal e demanda expansão das emissões.

No que diz respeito à reforma política, o processo também evoluiu gradativamente atê atingir a posição limite em que se encontra atualmente.

A reforma começou com modificaçōes constitucionais que permitiram a criação de um novo Parlamento da União, eleito não mais por candidatos indicados exclusivamente pelo Partido Comunista, embora com um terço dos seus membros indicado por organismos da sociedade civil, inclusive pelo próprio Partido Comunista. Previu-se um sistema de rodízio para a composição do Soviete Supremo e uma rotatividade no poder, de tal sorte que os eleitos para cargos públicos não podem exercê-los por mais de duas legislaturas, isto é, por mais de dez anos. Foram criadas comissões legislativas permanentes, inclusive a de Vigilância da Constituição; e comissões para o estabelecimento do estado de direito; nas eleições republicanas e locais já se eliminou a indicação de deputados, sendo todos eleitos por escrutínio direto e universal. Suprimiu-se, em seguida, o artigo
1 Pavel Bunitch, "Arendnyi Sektor. Resultati, Perspektivi" "Setor de arrendamento. Resultados, perspectivas") In Ekonomica I Gizn, $\mathrm{n}^{\mathrm{2}} 24$, junho de 1990.

2 Ekonomica i Gizn, $n^{2} 49$, dezambro de 1990. Năo Inclul as cooperativas agricolas.

3 S. Evstratov, "Sovmestnie Predpriaiya posle Starta" ("Joint Ventures após a partida") in Ekonomica i Gizn, $n^{2} 4$, janeiro de 1990.

4 The Soviet Economy. Systemic Crisis, Political Stabillty \& Inflation. Săo Paulo, Instituto Fernand Braudel de Economia Mundial, Mimeo, 1991.

5 "Narodnoe Khozlaistvo SSSR v 1989 g" ("Economia Nacional da URSS"), in Financi I Statistika, Moskva Goskomstat, 1990.

6 Como se sabe, as transaçós entre as empresas săo realizadas com moeda de conta, circulando a moeda flduclária somente nas transaçoes reallzadas entre os consumidores $\theta 0$ co mércio (e os serviços) no varejo. Ver Lonina Pomeranz, "Introduçăo", in Lenina Pomeranz (org.) Perestróika. Desafios da transformaçăo social na URSS. Sáo Paulo, Edusp, 1990. 

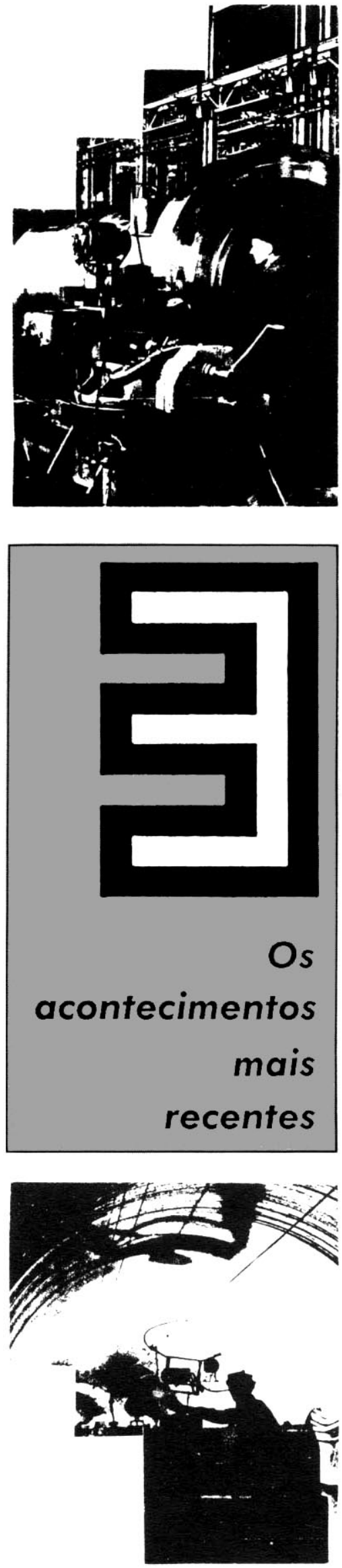

$\begin{array}{lllllll}R & E & V & \text { I } & S & T & A\end{array}$
60 da Constituição soviética, que dava ao Partido Comunista a condução do paŕs, com isso abrindo-se caminho para o pluripartidarismo. Instituiu-se a Presidência, devendo o presidente ser eleito diretamente a partir da próxima legislatura. E criou-se o Conselho Presidencial. Com a abertura democrática e o processo de reforma política, verificou-se uma grande ativização política, particularmente em torno da realização das eleições. Surgiram organizações e movimentos os mais variados, que se constitúram em embriốes de novos partidos ${ }^{(7)}$ e base do movimento nacionalista nas diversas repúblicas; as manifestações de rua incluíram-se entre as formas de atuação polf́tica; as pesquisas de opinião pública passaram a refletir uma conscientização distinta e os ânimos da população a favor das mudanças. $O$ processo de reforma polftica revelou-se, entretanto, incompleto, porque não atingiu os poderes executivos, nos diferentes niveis de governo. Criou-se, assim, uma dualidade de poder que contribuiu, ao lado das crescentes dificuldades na esfera econômica, para desacreditar os esforços de reforma e para aumentar as desconfianças no governo e na própria perestroika por ele deslanchada.

A atividade política intensificou-se e ganhou novos contornos com a eclosão de movimentos grevistas e a tentativa de formação de organizações sindicais independentes, com o aumento das demandas nacionalistas por soberania e independência nas repúblicas e com uma maior polarização das forças em conflito. A "revolução do alto" começou a ser questionada pela "revolução de baixo", isto é, o processo de transformações deslanchadas do alto começou a ficar fora de controle.

A primeira reação aberta contra os rumos da perestroika ocorreu no XXVIII Congresso do PCUS, realizado no verão de 1990, quando uma fração dos participantes entre eles, altas patentes das forças armadas - de maneira organizada e agressiva criticou o rumo das reformas e pretendeu eleger Ligachev como vice-secretário do PC. Minoritária no Congresso, esta fração partiu para a constituição do PC da República Federativa da Rússia, numa tentativa de controle do poder político nessa república.

A resposta a esses fatos foi não só o desligamento do PC, de Yeltsin, Popov e Sovchak, respectivamente presidentes dos sovietes da República, de Moscou e de Leningrado, e de 54 deputados do Congr. de Dep. do Povo da R. F. da Rússia, como ainda uma rebeldia de parcelas significativas da inteligentsia pertencente aos quadros partidários em aceitar a nova organização e o seu comando ${ }^{(8)}$. $O$ processo de polarização política acentuou-se, com o parlamento russo, sob o comando de Yeltsin, passando a liderar as posições reformistas. $O$ foco centrou-se nos programas de estabilização e reforma econômica, para os quais convergiram os embates políticos. Os programas alternativos eram basicamente dois: o do governo, cuja primeira redação resultou de uma comissão chefiada por A. Aganbeguián para formulá-lo, a partir de várias proposições que surgiram durante a discussão e rejeição dos programas apresentados pelo primeiro-ministro Rijkov ao Soviete Supremo em maio e setembro; e o Programa dos 500 Dias, elaborado por uma equipe constituída, por força dos entendimentos entre Yeltsin e Gorbatchev, de assessores de ambos e comandada por S. Shatalin, membro do Conselho Presidencial. Este programa, tamberm conhecido por Programa Shatalin, tomou por base trabalhos anteriores realizados por equipes paralelas; uma composta por jovens economistas, assessores da comissão estatal de reforma econômica, posteriormente agregados ao governo da R. F. da Rússia, que elaborou um programa de terapia de choque de $\mathbf{4 0 0}$ dias; e uma chefiada por N. Petrakov, assessor da presidência, mais concentrada na preparação de um pacote de leis e decretos que deveriam servir de base institucional para o ajustamento monetário e fiscal e a estruturação acionária da indústria( ${ }^{(9)}$.

O Parlamento rejeitou o Programa dos 500 Dias, com base nas objeções feitas por Rijkov e Abálkin, sugerindo que o presidente buscasse uma solução de compromisso entre os programas alternativos existentes, ate meados de outubro. Com efeito, em 19 desse mês, foi aprovado o documento Diretrizes Básicas para a Estabilização da Economia e a Passagem à Economia de Mercado, novamente redigido por A. Aganbeguián, com base no Programa dos 500 Dias. Ao mesmo tempo, foram concedidos a Gorbatchev, por sua solicitação, poderes extraordinários até março de 1992, para adotar as medidas necessárias ao enfrentamento da situação econômica e à passagem para a economia de mercado.

Não cabe aqui fazer uma análise detalhada de ambos os documentos. Conforme a opinião de um conhecido sovietólogo americano, economista Ed Hewett, o plano presidencial aprovado - as Diretrizes - segue a mesma linha do plano Shatalin, não obstante algumas diferenças cronológicas em relação aos preços e à desestatização(10). De fato, 
comparados ambos os textos(11), verifica-se que: a) em ambos se contempla a execução de um programa de estabilização que tem como centro um saneamento monetário e fiscal, no qual se determina delimitação do déficit orçamentạ́rio e controle das emissões para financiá-lo; propõe-se uma modificação da estrutura e base da taxação e cortes dos gastos, inclusive do setor de defesa e de segurança interna (no Programa dos 500 Dias especifica-se o nível dos cortes no orçamento de 1991, o que não é feito nas Diretrizes), bem como a supressão dos subsídios às empresas deficitárias; a diferença aparece em relação à construção inacabada - no Programa dos 500 Dias prevê-se vendê-la, depois de devidamente avaliada, enquanto nas Diretrizes só há menção de suprimi-la, ou seja, de não completá-la, a não ser quando se trata de investimentos dirigidos à produção de bens de consumo; b) em ambos os programas mantém-se temporária e parcialmente o controle de preços e o mecanismo de encomendas (contratos) estatais, para evitar uma queda muito acentuada da produção; c) em ambos os programas propõe-se uma reforma bancária que confere ao Banco Central o controle da política monetária desvinculada do governo; d) em ambos esboça-se a preocupação com o excesso de liquidez e a necessidade de equilibrar o mercado de bens de consumo; e) e em ambos prevê-se programas de garantias sociais contra as conseqüências perversas da execução do programa, ou seja, contra a elevação explosiva dos preços e o desemprego.

Alêm do programa de estabilização, ambos os programas propõem a desestatização com uma trajetória similar, que prevê o iń́cio do processo nos setores em que sua implantação parece mais fácil: comércio e serviços pessoais, pequenas e médias empresas. (No Programa dos 500 Dias, porém, o ritmo da privatização é mais intenso.) $\mathrm{E}$ em ambos definem-se como setores a permanecer estatizados a infra-estrutura econômica básica - energia, transportes, comunicações -, a defesa e, no caso particular das Diretrizes, a pesquisa espacial e ciência e tecnologia. Em ambos se contempla um programa de reforma agrária, definindo-se mais detalhadamente no Programa dos 500 Dias os objetivos quantitativos a alcançar.

A diferença entre os dois programas está essencialmente na forma de sua implementação, forma através da qual se define o comando e o controle do processo de reforma. São dois, basicamente, os traços que, interdependentemente, nesse sentido, distinguem os dois programas. O primeiro é o relacionamento entre o Centro e as Repúblicas. Há consenso nos dois programas sobre a necessidade de manter um mercado econômico comum e, conseqüentemente, uma única moeda e um único sistema tarifário e cambial. Isso, ao lado das áreas já referidas anteriormente, leva à necessidade de manter-se um conjunto de órgãos centrais e um comando central para aspectos essenciais da política econômica. Entretanto, para que a soberania das repúblicas seja salvaguardada, o Programa dos 500 Dias pressupõe maior autonomia às repúblicas, as quais, acordando voluntariamente as linhas de união econômica entre elas, na forma de uma confederação, delegariam parcela dos seus direitos de gestão ao poder central. Nas Diretrizes afirmase a soberania e a igualdade das repúblicas, mas nos marcos de uma integridade da União como federação. E, alêm de atribuir-se a órgãos centrais a regulamentação das condições iniciais de passagem das repúblicas para uma economia de mercado, criam-se fundos centralizados de desenvolvimento regional, de divisas e de estabilização, tambêm regulados centralmente. Não obstante se preveja, como no Programa dos 500 Dias, a constituição de um Comitê Econômico Inter-Republicano, para coordenação das atividades que devem ser realizadas pelas repúblicas, de fato criou-se junto à presidência da URSS um Conselho da Federação, composto pelos presidentes dos sovietes das quinze repúblicas, o qual substituiu o dissolvido Conselho Presidencial.

O segundo traço a distinguir os dois programas, na realidade corolário do primeiro, é a outorga de plenos poderes a Gorbatchev, para legislar por decreto, dando à execução das Diretrizes um caráter altamente centralizador e autoritário. Estas não foram acompanhadas de projetos de lei para discussão no Soviete Supremo, ficando de fato como diretrizes para a ação do presidente. Na medida em que Gorbatchev, de acordo com as pesquisas de opinião pública, perde a confiança da população que o identifica com os conservadores do PC a quem ela atribui o estado a que chegou o país, o exercício dos poderes que lhe foram conferidos conduz à adoção de métodos repressivos de gestão e a um recuo na abertura democrática; a expressão dessa conduta é a formação de milícias mistas do exército, polícia civil e $\mathrm{KGB}$, devidamente autorizadas para vistoriar empresas, inclusive estrangeiras, a pretexto de combater o crime organizado ${ }^{(12)}$; e a acusação, feita pelo primeiro-ministro Pavlov, de uma conspiração econômica, envolvendo bancos estrangeiros, contra o governo, para justificar o drástico recolhimento das notas de 50 e
7 Segundo o jornal Novedades de Mos cu, de 15/7/1990, havia nessa data onze grupos polfticos em perspectiva de transformarem-se em partidos.

8 Ver L Pomeranz, Observaçסes sobre a evoluçăo da perestróika na URSS Săo Paulo, Instituto de Estudos Avançados da USP. Coleção Documentos, Sórle Assuntos Internacionais, $n^{2} 9$, agosto de 1990 .

9 L Grigoriev, Ekonomitcheskyi Monitor (Monitor económico), MEMO, novembro de 1990.

10 The New Soviet Plan. Foreign Affairs, Winter 1990/91.

11 Infelizmente teve-se acesso somente a um resumo do texto do Programa un 500 Dias, que fol dos 500 Dlas, que tol edltado em dois olumes, um dos quals contendo $\mathrm{m}$ nutas dos autos legislativos. A análse que se segue apóla-se no texto de Hewett (nota 9) e em P. Desal, Sovie Economic Reform: a Tale of Two Plans, New York, The Harriman Ins titute Forum, Vol. 3, $n^{2} 12$, december 1990.

12 Há ainda acusaçరes de membros da oposiçăo, de que estas mesmas milif cias seriam usadas para conter descontentamento popular provocado pela alta dos preços de bens de con sumo anunciada para $1^{2}$ de abril. mesmo acompanhada da promessa de cossa de compensaçoes salarlais. Aparente( a julgar pelos acontecimentos em Minsk, capital da Blelo-Rússia, essas acusaçठos revelaram-se infundadas.

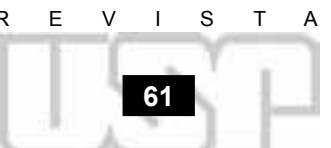


13 Inevitável porque o aumento concedido aos preços de atacado a partir de $1^{2}$ de janeiro, mantidos flxos os preços de varejo, passou a exigir um aumento dos subsidlos ao consumo $\theta$ consequentemente, a pressionar orçamento.

14 Alêm da reuniăo realizada no ano passado entre Gorbatchev e dirigentes das empresas estatais, ver noticlário sobre o Congresso da Uniắo Clentffica Industrial, presidido por A. Volski (participante da missôno GorVolski (partcipanto da missâ Gorparam empresas de diferentes formas de propriedade e tamanho. Ekonomica i Gizn, n²11, março de 1991.

15 Juntas, estas repóblicas perfazem mals de $85 \%$ do Produto Social Bruto do pals. Conforme A. Illarionov, "Ekonomitcheskyi Potentsial i urovni ekonomitcheskovo razvitya coluznix respublik" ("Potencial economico e nivels de desenvolvimento económico n(vels de desenvolvimento economico
das repúblicas soviéticas"), in Voproci Ekonomiki, $n^{2} 4,1990$.

16 A proposta preliminar fol alterada posteriormente, de maneira a introposteriormente, de maneira a introcas. A primeira proposta fol publicada na Izvestia, diârio do Congresso dos Deputados do Povo da URSS, no dia 24 de novembro de 1990. Infelizmente năo foi possivel obter uma versăo da segunda proposta, da qual só um resumo multo sumárlo fol publice do no Jornal do Brasil, em artigo reproduzido do Baltimore Sun.

17 Conforme Serge Schmemann, no New York Times, reproduzldo em O Estado de S. Paulo, 29/3/1991.
100 rublos e o estabelecimento de regras para a troca dessas notas em poder da população e para a liberação das poupanças. Seguiram-se a isso o inevitável ${ }^{(13)}$ aumento dos preços de varejo e declaraçōes sobre o retorno temporário aos métodos de gestão administrativa centralizada, como forma de contornar as dificuldades e deter a queda da produção. Convém acrescentar que esses atos são respaldados pela pressão exercida por diferentes núcleos de dirigentes empresariais ${ }^{(14)}$.

Esta postura no plano econômico é complementada pelo não reconhecimento e anulação das leis editadas nos sovietes das repúblicas, que contrariam as normas e atos centrais, acentuando o conflito político entre o Centro e as repúblicas, em torno das quais passa, assim, a polarizar-se a luta pelo aprofundamento do processo democrático.

A observação desse conflito revela, por um lado, um avanço político das forças conservadoras, nos postos de comando do país: depois da substituição do ministro do Interior, V. Bakatin e da demissão voluntária de Petrakov e Shatalin do Conselho Presidencial e de Abálkin do cargo de primeiro-vice-ministro e da presidência da Comissão de Reforma Econômica, seguiu-se a substituição de vinte ministros e a dramática demissão-denúncia de Chevardnadze. Embora não se conheça ainda os termos de seu discurso ao Parlamento, sabe-se que a sua saída do governo deve-se a pressões relacionadas com a política externa da URSS por ele conduzida, à qual são atribuŕdas as mudanças no equilíbrio de poder mundial e a perda de posição do país no cenário internacional.

A esse quadro soma-se a tentativa de organização dos Comitês de Salvação Nacional, como instrumentos para a destituição dos governos de algumas repúblicas e a ação armada na Lituânia, que provocou veementes protestos, tanto no exterior quanto no interior do país. A reação do poder central aos protestos foi dúbia: ao mesmo tempo que formalmente procedeu a um recuo político, não assumindo responsabilidade pela ação militar, reinstaurou a censura na TV e no rádio, que permanecem sob firme controle do Comitê Estatal de Rádio e TV. Do outro lado, observa-se um esforço de dupla direção, conduzido a partir da R. F. da Rússia; em uma delas, busca-se o estabelecimento de acordos de cooperação econômica e política entre ela e outras repúblicas, particularmente Ucrânia, Bielo-Rússia e Cazaquistão(15), além de apoiar as repúblicas do Báltico nos seus objetivos de independência; em outra, busca-se articular as forças da oposição, dispersas em várias agrupações, em torno do movimento Rússia Democrática.

Nesse processo, Yeltsin, presidente da R. F. da Rússia, cresce como líder da oposição, não obstante o seu comportamento intempestuoso e, em certa medida, demagógico, e as muitas dúvidas que a sua liderança por isso coloca, inclusive nos círculos políticos do exterior.

O fato político de maior notoriedade recentemente foi a realização do plebiscito sobre o novo Tratado da União, proposto por Gorbatchev(16). Não há ainda análises consistentes sobre os resultados obtidos, devido à não-participação de seis repúblicas, ainda que pequenas - menos de $10 \%$ da população do país - , aos resultados apertados para o governo em alguns centros urbanos importantes como Moscou, Leningrado e Sverdlov, e à vitória do NĀO, portanto derrota do governo, em Kiev, capital da Ucrânia; além das dificuldades de conciliar os resultados da pergunta central formulada com as perguntas de âmbito local introduzidas, entre outros, na República da Rússia e em Moscou, sobre a realização de eleições diretas para a chefia dos respectivos governos. Uma primeira conseqüência desses resultados $-71 \%$ a favor de eleiçōes diretas para a presidência da R. F. da Rússia e $76 \%$ a favor da proposta Gorbatchev - foi a impossibilidade política de votar o impedimento de Yeltsin da presidência do Parlamento russo, auxiliada ainda pelas demonstrações de apoio ao mesmo realizadas em Moscou, a despeito da sua proibição decretada por Gorbatchev e do aparato policial mobilizado para impedi-las. Cabe ainda destacar a posição assumida pelo Parlamento russo contra a interferência do poder central em atribuições de sua competência - a manutenção da ordem pública - revertendo a direção que se pretendia imprimir aos seus trabalhos, de condenação e impedimento de Yeltsin. Com base no plebiscito e no respaldo do Parlamento, Yeltsin convocou eleiçōes diretas para a presidência da R. F. da Rússia para 12 de junho próximo.

Posteriormente, a república da Geórgia realizou o seu próprio plebiscito - foi uma das repúblicas que não participou do plebiscito geral convocado pelo governo central e, com base em seus resultados, estrondosamente a favor da independência, proclamou desobediência e sabotagem ao governo central.

Resta, para fechar o quadro polf́tico, a manutenção da greve dos mineiros, iniciada no começo de março, e que, alcançando 200 das 580 minas de carvão existentes na 
Rússia e na Ucrânia(17), já afeta a produção da indústria siderúrgica. Nesta greve, além das reivindicações econômicas por aumento de salário e melhoria das condições de trabalho e sociais, os mineiros exigem a demissão de Gorbatchev e a dissolução do Parlamento da União. De acordo com noticiário de imprensa, embora a liderança tenha aceito as propostas de aumento salarial feitas pelo primeiro-ministro Pavlov, os trabalhadores as rejeitaram, prosseguindo na greve. O movimento foi apoiado em várias partes do país, em algumas delas inclusive por greves, e levou, em alguns casos, à passagem da propriedade das minas, da União para a república, como primeiro passo para a sua desestatização. A greve, entretanto, continua na Sibéria e na Ucrânia, já causando queda de produção na siderurgia. $\mathrm{O}$ governo, com o deslocamento de Pavlov até a região mineira, para negociações com os grevistas, revelou disposição para o diálogo. Mas tem um plano de emergência que deverá ser proximamente submetido ao Parlamento e no qual, entre outras medidas, se contempla a proibição de greves políticas.

O cenário é, portanto, de confrontação política, multiplicando-se as indagações sobre a manutenção de Gorbatchev no poder e sobre a volta à ditadura, com retrocesso inclusive na política externa da URSS. A confrontação política está, porém, induzindo a chamamentos de moderação e a apelos para negociações entre as partes em confronto, personalizadas nas lideranças de Yeltsin e Gorbatchev. A proposta, avançada por Yeltsin, para a realização de uma mesa-redonda das forças sociais e políticas representativas do país nos moldes das realizadas na Polônia no início dos anos 80 , e tendo em vista um governo de coalizão, foi inicialmente rechaçada por Gorbatchev. Mas há novas indicações na imprensa de que algo pode ser encetado nessa direção, dependendo dos resultados da reunião plenária do PCUS a realizar-se em abril e da aprovação ou não, pelo Parlamento, do plano de emergência a ser apresentado por Gorbatchev. Como se sabe, em ambos os casos está em jogo a própria posição de Gorbatchev, como secretário geral do PCUS e presidente do país, respectivamente.

A descrição sumária que foi feita da evolução da perestroika mostra a natureza conflitiva e contraditória que assume no decorrer de sua implantação. Não se deveria esperar que fosse diferente essa trajetớria, uma vez que as mudanças sociais não se fazem sem conflito ou linearmente, sem retrocessos e alterações de rumo; mormente quando se trata de mudanças de profundidade como as contempladas na perestroika. As questões que parecem relevantes para se responder a pergunta posta dizem respeito: a) à necessidade objetiva das transformações propostas; e b) ao grau de avanço já realizado em sua direção e às conseqüências disso resultantes para o prosseguimento do processo de transformação.

Em relação à primeira questão, o diagnóstico que levou à perestroika parece claro: o modelo de organização social anterior esgotou-se. Do ponto de vista econômico, o seu esgotamento vem se fazendo sentir jâ há bastante tempo, não só pelos indicadores de desempenho da economia, como tamberm pelas inúmeras tentativas de reforma encetadas desde a metade dos anos 50. O que desponta como novo, no diagnóstico mais recente, é o reconhecimento de que este esgotamento está associado às formas de gestão e estas, por sua vez, estão associadas ao mecanismo mais amplo de funcionamento do sistema. O que significa, em outros termos, que ê todo o modelo de organização social que está esgotado, demandando transformações.

Do ponto de vista econômico, existe consenso sobre o caminho a seguir: a descentralização do processo decisório e a regulamentação da economia através dos mecanismos de mercado e de sua gestão indireta, por meio das polf́ticas econômicas. Este consenso fica evidente no conteúdo dos programas econômicos, tanto da oposição quanto do governo, sendo de se destacar a afirmação, no preâmbulo deste último, de que não há outra alternativa ao mercado.

As divergências aparecem no plano político-institucional, quando o que se disputa é a detenção do poder político e o controle do processo de transformação. Neste sentido, há que se considerar, por um lado, a disputa sobre o grau de regulamentação do mercado e sobre a duração do período de ajustamento e transição, durante o qual devem se acomodar os diferentes interesses; assinale-se, neste particular, a observação contida no texto de Golovkov e Kagalovski acima mencionado, sobre o "vigoroso movimento de privatização... conduzido por enérgicos diretores de empresas e outros membros do establishment estatal e partidário". Por outro lado, não cabe subestimar o efeito que exerce a direção tomada pelas transformações realizadas nos países do Leste europeu e o cunho ideologico que perpassa os conflitos políticos na URSS. Não se trata somente de
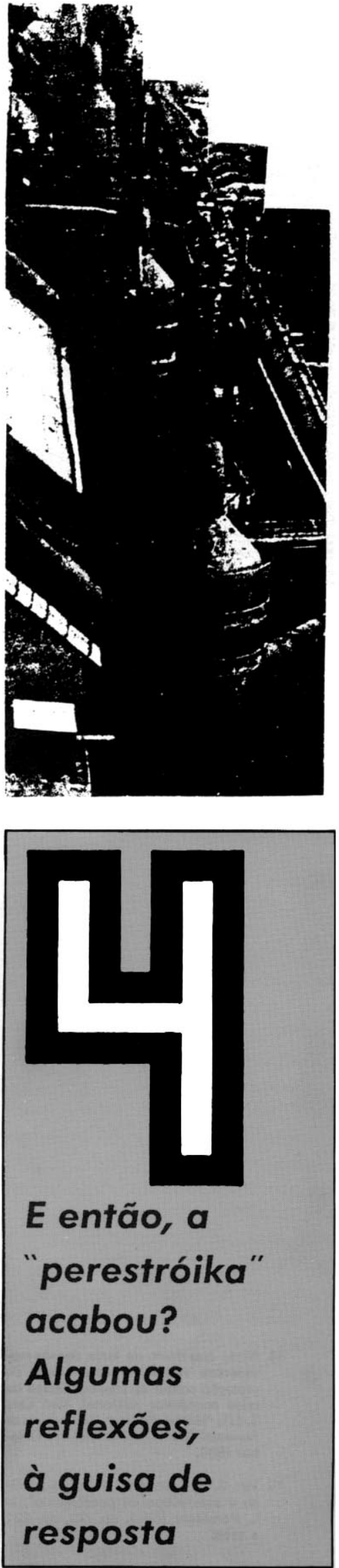


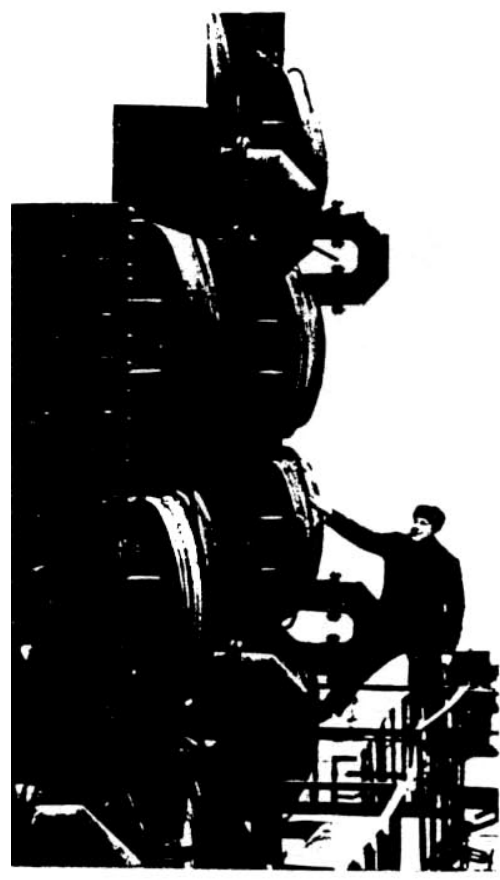

uma troca de grupos no poder, mas de uma batalha para definir os novos contornos do sistema transformado, mantendo-o nos marcos de um socialismo ainda não bem-definido, em função do perfil de seus defensores, ou modificando-o segundo os moldes dos países capitalistas avançados do Ocidente.

Neste contexto inserem-se como questões ainda não resolvidas a da democracia, proclamada com a perestroika, como valor universal e necessário para o desenvolvimento da individualidade anteriormente esmagada e para a inserção do país, como dizem os soviéticos, no mundo das nações civilizadas; e a do papel que deve exercer a URSS na reorganização do poder político mundial, questão essa que assumiu a maior relevância durante o conflito no Golfo Pérsico.

Quanto ao grau de avanço desse processo, este texto pretendeu fornecer indicações para interpretação. Embora talvez mais lento do que a expectativa, o sistema econômico se transforma: o velho sistema de suprimento centralizado se desmorona, assim como as restrições financeiras à autonomia decisória das empresas. A desestatização e a privatização passam para o centro dos debates, surgindo as primeiras organizações empresariais no plano institucional. A desorganização econômica vigente vem sendo enfrentada de forma intempestiva e arbitrária, com recurso a certa volta aos comandos administrativos. Mas, por força mesmo do grau de desmoronamento do sistema anterior e dos custos já inflingidos à população, por um lado; e por força da glasnost e do descrédito nos órgãos centrais, por outro, um retorno ao sistema anterior só parece plausível ou no quadro de uma ditadura violenta ou em caráter realmente temporário e parcial, para permitir as acomodações de interesses a que se fez referência. Há, naturalmente, que levar na devida conta o peso que representa, no descrédito referido, a avaliação entre camadas ponderáveis da população de que a desordem econômica corrente, por elas identificada com o desabastecimento, o mercado negro e os preços considerados especulativos, é de responsabilidade da perestroika e de quem a introduziu. Isso talvez ajude a explicar o crescimento das demandas pela renúncia de Gorbatchev, especialmente em repúblicas como a Bielo-Rússia, em que não é tão forte o movimento democrático.

No que concerne especificamente ao avanço da democracia, não obstante os recuos assinalados anteriormente, há que observar a resistência, seja dos jornalistas e da intelectualidade contra a censura, seja da população que, em manifestações de massa, demonstra perda de medo e desobediência às proibições decretadas. $\mathrm{E} o$ insucesso das tentativas de desestabilização dos governos republicanos através dos Comitês de Salvação Nacional, em aliança esdrúxula entre setores do PC e do exército. Neste particular, é primordial a característica que assume o movimento pela democracia, de realizar-se com base nas repúblicas e no sentimento nacional(18). Se, por um lado, isso traz o risco do exacerbamento do chauvinismo e do conflito étnico, por outro, na sua disputa com o centro, introduz um forte fator de resistência às intenções de centralização autoritária, jogando a favor da democracia. Especial atenção merece esse movimento na República Federativa da Rússia onde, não obstante o chauvinismo organizado, concentra-se o maior e o mais diversificado contingente das forças democráticas, em razão mesmo da peculiaridade de sua posição anterior na União, que lhe assegurou a maior proeminência econômica e cultural do país ${ }^{(19)}$. É a partir da R. F. da Rússia, que dispõe ademais de um líder de grande popularidade, que estão sendo buscados acordos diretos entre as repúblicas e propostas negociações com o Centro, para contornar o confronto que caracteriza o atual quadro político da URSS.

Para finalizar estas reflexões e deixar aos leitores a resposta à pergunta-tema deste artigo, resta a questão da política externa da URSS. Este é um ponto extremamente delicado, porque envolve, além de outros aspectos, a posição do establishment militar, pouco conhecida ou induzida indiretamente pelos acontecimentos, como a renúncia de Chevardnadze e a tentativa de uma ação intermediadora no conflito no Golfo Pérsico. E envolve, tambêm, a postura dos países ocidentais.

Uma avaliação mais apurada cabe, portanto, a especialistas estratégicos e de política exterior. Somente a título de contribuição para essa avaliação, cabe chamar atenção para o que representaria, para os esforços de reconstrução econômica do sistema, a manutenção dos enormes dispêndios com a defesa e a pesquisa espacial, e a ruptura da assistência técnica e financeira do exterior, que seriam as conseqüências mais imediatas de uma mudança de rumos na política externa deslanchada com a perestroika. A abertura para a Ásia, embora de resultados ainda pouco claros, anima a pensar que, por ora, as posições a respeito não estão definidas. 